\title{
PERSEPSI AUDITOR ATAS EFEK TEKANAN ANGGARAN WAKTU, BUDAYA ETIS ORGANISASI DAN KOMITMEN PROFESIONAL TERHADAP PERILAKU AUDIT DISFUNGSIONAL
}

\section{Auditor Perception About The Effect Of Budget Time Pressure, Ethical Organizational Culture And Professional Commitment On Disfunctional Audit Behaviour}

\author{
Nien Rezkyanti ${ }^{1}$ \\ Email: nienrezkyanti@gmail.com \\ Magister Sains Akuntansi, Universitas Hasanuddin, Makassar \\ Jl. Perintis Kemerdekaan Km.10. Makassar, 90245. Sulawesi Selatan \\ Edy Fitriawan $\mathbf{S}^{2}$ \\ Email: edifsyahadat@unsulbar.ac.id \\ Prodi Akuntansi Fakultas Ekonomi Unsulbar \\ Jl. Prof. Dr. Baharuddin Lopa, S.H., Baurung, Banggae Timur, Baurung, Banggae \\ Tim., Kabupaten Majene, Sulawesi Barat
}

\begin{abstract}
ABSTRAK
Asepk perilaku menjadi faktor yang menentukan bagi audtior dalam melaksanakan tugas pemeriksaannya. Penelitian ini bertujuan untuk mengetahui pengaruh budaya etis organisasi, komitmen profesional, dan tekanan anggaran waktu terhadap perilaku audit disfungsional. Sampel penelitian ini terdiri dari 84 auditor BPK perwakilan Provinsi Sulawesi Selatan. Data penelitian ini adalah data primer yang besumber dari penyebaran kuesioner. Pengaruh budaya etis organisasi, komitmen profesional, dan tekanan anggaran waktu terhadap perilaku audit disfungsional dianalisis dengan menggunakan regresi linear berganda. Hasil empiris penelitian membuktikan bahwa budaya etis organisasi, komitmen profesional, secara parsial berpengaruh negatif dan signifikan terhadap perilaku audit disfungsional. Sementaraa itu, tekanan anggaran waktu berpengaruh positif terhadap perilaku audit disfungsional. Budaya etis organisasi dan komitmen profesional terhadap profesi auditor dapat menurunkan perilaku tidak etis auditor yang dapat mengurangi kualitas hasil pemeriksaan dalam tugas pemeriksaan. Sementara itu, tekanan waktu yang dirasakan oleh auditor pada tugas pemeriksaan dapat menyebabkan munculnya tindakan oportunis dan tidak etis dari auditor. Hal ini akan berimbas pada menurunya kualitas hasil pemeriksaan.
\end{abstract}

Kata kunci: Disfungsional; perilaku; komitmen; tekanan; kualitas audit. 


\begin{abstract}
Aspects of behavior becomes the determining factor for the auditors in carrying out the task of examination. This study aimed to analyze the influence of ethical organizational culture, professional commitment, and time budget pressure on disfunctional audit behavior. The research samples comprised of 84 representatives BPK auditor as South Sulawesi province. This research data is primary data from questionnaires besumber. The influence of ethical organizational culture, professional commitment, and time budget pressure on audit dysfunctional behavior were analyzed using multiple linear regression. The researach results revealed that the organization ethical culture, professional commitment, partially had negative and significant effect on dysfunctional audit behavior of. While the budget pressure had a positive effect on the dysfunctional audit behavior. The effect of the organizational ethical culture and the professional commitmen on the auditors's reduce the quality of the examination result of the inspection tasks. Meanwhile, time pressure felt by the auditors in their inspection tasks could cause the opportunistic and unethical actions of the auditors.
\end{abstract}

Keywords: Disfungsional; behavior; commitment; pressure; audit quality.

\title{
PENDAHULUAN
}

Perilaku auditor, selain kompetensi dan independensi menjadi faktor yang menarik dan telah diteliti oleh banyak peneliti dalam kaitannya dengan kualitas audit. Secara spesifik, perilaku auditor yang menyimpang dari prosedur yang telah ditetapkan (perilaku disfungsional) akan meningkatkan kualitas hasil pemeriksaan, dan begitupun sebaliknya. Lightner et al (1982), menemukan bahwa $63 \%$ dari total auditor yang menjadi responden penelitiannya pernah melakukan perilaku audit disfungsional, yakni underreporting atau tidak melaporkan tambahan waktu yang mereka gunakan dalam pelaksanaan audit. Selanjutnya, Willet \& Page (1996), melakukan penelitian pada auditor junior Kantor Akuntan Publik, hasilnya ditemukan bahwa 70 persen dari responden penelitiannya pernah melakukan praktik "irreguler auditing".

Otley \& Pierce (1996); Lightner et al (1982), menyatakan bahwa perilaku audit disfungsional yang terkadang dilakukan auditor dalam menyelesaikan tugas audit mengakibatkan adanya ancaman terjadinya penurunan kualitas audit baik secara langsung maupun tidak langsung. Tindakan-tindakan yang dilakukan auditor dalam pelaksanaan program audit yang dapat mereduksi kualitas audit secara langsung disebut sebagai perilaku reduksi kualitas audit (audit quality 
reduction behaviors) seperti penghentian premature prosedur audit, review yang minim atas dokumen auditee, tidak menginvestigasi kesesuaian perlakuan akuntansi yang diterapkan auditee, penerimaan atas penjelasan auditee yang tidak memadai, mengurangi pekerjaan audit dari yang seharusnya dilakukan, dan tidak memperluas jangkauan pengauditan ketika terdeteksi transaksi atau pos yang meragukan, sedangkan yang dapat mereduksi kualitas audit secara tidak langsung disebut perilaku underreporting of time adalah kurangnya pelaporan waktu, yang terjadi ketika auditor menyelesaikan pekerjaan yang dibebankan dengan waktu mereka sendiri.

Trevino (1986), mengemukakan bahwa perilaku tidak etis yang dilakukan oleh individu dalam organisasi diakibatkan oleh karakteristik individual, situasional maupun interaksi keduanya. Hal ini didasarkan pada model interaksional pengambilan keputusan. Selain itu, beberapa temuan penelitian terdahulu yaitu Otley \& Pierce (1996); Silaban (2009); Svanberg \& Ohman (2013); Sweeney et al (2010); Kaplan \& Whitecotton (2001), menyatakan bahwa faktor-faktor situasional (seperti tekanan anggaran waktu dan budaya etis organisasi) dan faktor individu (seperti komitmen professional) memiliki pengaruh terhadap perilaku audit disfungsional dalam pelaksanaan program audit.

Rhode dalam Coram et al (2003), menemukan bahwa tekanan anggaran waktu adalah masalah bagi auditor pada semua level. Coram et al (2003), melakukan penelitian pada 43 auditor pemula yang berkerja pada KAP di Australia menemukan bahwa lebih dari 50\% responden mengalami tekanan anggaran waktu yang tinggi dalam melaksanakan prosedur audit. Otley \& Pierce (1996), menemukan bahwa kendala anggaran waktu menjadi faktor utama yang mendorong auditor melakukan perilaku audit disfungsional. Raghunathan (1991), juga menemukan hal yang sama bahwa auditor yang merasakan tekanan anggaran waktu menjadi penyebab terjadi perilaku audit disfungsional. Alasannya adalah karena faktor ini dapat mengakibatkan auditor merasakan tekanan dalam pelaksanaan program audit yang disebabkan ketidakseimbangan antara waktu yang tersedia dengan waktu yang dibutuhkan untuk menyelesaikan tugas audit (Kelley \& Seiler, 1982). Hal serupa ditemukan oleh Silaban (2009), yang hasilnya 
menunjukkan bahwa tekanan anggaran waktu berpengaruh positif dan signifikan terhadap perilaku disfungsional auditor. Hasil ini menunjukkan bahwa semakin tinggi tekanan anggaran waktu maka perilaku audit disfungsional juga semakin tinggi. Dengan kata lain, tekanan anggaran waktu yang tinggi mendorong perilaku audit disfungsional dikalangan auditor pada KAP. Hasil yang tidak sejalan ditemukan oleh Malone \& Robert (1996), menemukan bahwa ada pengaruh dari tekanan anggaran waktu terhadap perilaku disfungsional auditor tetapi pengaruhnya tidak signifikan.

Lightner et al (1982), menemukan bahwa faktor etika yang merupakan salah satu faktor yang dapat mengurangi terjadinya perilaku audit disfungsional. Hasil penelitian ini menyatakan bahwa kepercayaan seseorang atas norma yang dirasakan, menjadi faktor yang penting dalam menjelaskan apakah seorang auditor melakukan perilaku disfungsional audit dalam hal ini underreporting of time atau tidak. Svanberg \& Ohman (2013), melakukan penelitian pada 1.200 orang auditor di Swedia terkait dengan faktor situasional budaya etis organisasi. Hasil penelitiannya menemukan bahwa budaya etis organisasi berhubungan negatif dengan tekanan anggaran waktu. Svanberg \& Ohman (2013), menyatakan bahwa praktek penganggaran waktu audit yang ketat terjadi pada perusahaanperusahaan yang memiliki budaya etis organisasi yang lemah. Sedangkan untuk perusahaan yang memiliki budaya etis yang kuat dalam melakukan penyusunan anggaran mempertimbangkan respon auditor atas ketat atau tidaknya anggaran audit yang dibuat.

Choo (1986), melakukan penelitian pada 172 auditor terkait stress yang mereka alami dan menemukan bahwa auditor yang memiliki komitmen professional yang tinggi merasakan stress kerja pada level yang lebih rendah, begitupun sebaliknya auditor dengan komitmen professional yang rendah memiliki tingkat stress kerja yang lebih tinggi.

Penelitian ini bertujuan untuk menguji pengaruh budaya etis organisasi, komitmen profesional, dan tekanan anggaran waktu terhadap perilaku audit disfungsional. 


\section{METODE PENELITIAN}

\section{Jenis Penelitian}

Berdasarkan karakteristik masalah yang diteliti, penelitian ini merupakan penelitian survei yang bersifat causal study. Menurut Sarwono (2006), survei adalah studi yang bersifat kuantitatif yang digunakan untuk meneliti gejala suatu kelompok atau perilaku individu. Causal study merupakan studi dimana peneliti ingin menemukan penyebab dari suatu permasalahan.

\section{Waktu dan Lokasi Penelitian}

Penelitian ini dilaksanakan pada bulan Desember (2014) - Januari (2015). Penelitian ini dilakukan di Badan Pemeriksa Keuangan Republik Indonesia Perwakilan Sulawesi Selatan yang beralamat di jalan Andi Pangeran Pettarani.

\section{Populasi dan Sampel}

Populasi penelitian ini yaitu auditor yang merupakan pegawai tetap pada Badan Pemeriksa Keuangan Perwakilan Provinsi Sulawesi Selatan berjumlah 168 orang. Pemilihan sampel dalam penelitian ini menggunakan metode Purposive sampling dengan tujuan untuk mendapatkan sampel sesuai dengan kriteria yang ditentukan. Kriterianya adalah sebagai berikut: (1) Auditor yang telah mengikuti auditor ahli; (2) Auditor yang tidak dibebastugaskan dari jabatan fungsional pemeriksa. Jumlah sampel yang diteliti dalam penelitian ini sebanyak 84 auditor atas 124 jumlah kuesioner yang telah disebar.

\section{Pengumpulan Data}

Sumber data dalam penelitian ini adalah data primer yakni data yang diambil langsung dari pusat data atau melalui survei lapangan (Kuncoro, 2009). Dalam penelitian ini teknik pengumpulan data dilakukan melalui: (1) Kuisioner, yaitu mengumpulkan data dengan mengadakan angket/ pertanyaan-pertanyaan dari penelitian terdahulu oleh penulis yang disebarkan pada responden yang menjadi sampel penelitian. (2) Wawancara, yaitu wawancara yang dilakukan dengan beberapa auditor untuk mendapat gambaran mengenai perilaku disfungsional dan karakteristik personal auditor. (3) Dokumentasi, yaitu mengumpulkan data dengan 
mengambil data-data yang ada dan telah diolah baik dari tempat penelitian maupun perpustakaan.

\section{Analisis Data}

Analisis data dalam penelitian ini menggunakan regresi berganda (mutltiple regression). Analisis regresi dilakukan dengan terlebih dahulu menguji validitas dan reliabilitas data yang terkumpul, kemudian dilanjutkan dengan pengujian asumsi klasik, terdiri dari uji normalitas data, uji multikolonearitas, dan uji heteroskedastisitas. Persamaan regresi dalam penelitian ini dapat dirumuskan sebagai berikut:

Bagian 1, untuk menjawab hipotesis 1, 2, dan 3:

$$
\begin{aligned}
& Y_{2}=\alpha+b_{2} Y_{1} \\
& Y_{1}=\alpha+b_{1} X_{1} \\
& Y_{2}=\alpha+b_{3} X_{1}
\end{aligned}
$$

Bagian 2, untuk menjawab hipotesis 4 dan 5:

$$
\begin{aligned}
& Y_{1}=\alpha+b_{4} X_{2} \\
& Y_{2}=\alpha+b_{5} X_{2}
\end{aligned}
$$

\section{HASIL DAN PEMBAHASAN}

Hasil penelitian menunjukkan bahwa variabel tekanan anggaran waktu berpengaruh positif terhadap perilaku audit disfungsional (H1), dengan nilai koefisien sebesar 0,635 (positif) pada derajat signifikansi 0,05 (5\%). Artinya, semakin tinggi tekanan anggaran waktu, semakin tinggi pula kecenderungan untuk melakukan perilaku audit disfungsional. Dengan demikian, H1 diterima.

Variabel budaya etis organisasi berpengaruh negatif tekanan anggaran waktu $(\mathrm{H} 2)$, dengan nilai koefisien regresi sebesar -0,276. Hal ini berarti, semakin tinggi budaya organisasi dalam lembaga pemeriksa (BPK), semakin rendah tekanan anggaran waktu yang dirasakan pada saat melakukan tugas pemeriksaan. Dengan demikian, H2 diterima. Pengujian H3 menunjukkan bahwa budaya etis organisasi berpengaruh negatif dan signifikan terhadap perilaku audit disfungsional dengan nilai koefisien regresi sebesar -1,494. Hal ini berarti 
semakin tinggi budaya etis organisasi, semakin rendah perilaku audit disfungsional. Dengan demikian, H3 diterima.

Pengujian H4 menunjukkan bahwa variabel komitmen profesional berpengaruh negatif dan signifikan terhadap tekanan anggaran waktu dengan nilai koefisien regresi sebesar -0,183. Artinya, semakin tinggi komitmen auditor BPK terhadap profesi mereka, semakin rendah tekanan anggaran waktu yang dirasakan. Dengan demikian, H4 diterima. Sementara itu, hasil pengujian H5 menunjukkan bahwa variabel komitmen profesional berpengaruh negatif dan signifikan terhadap perilaku disfungsional audit. Artinya, semakin tinggi komitmen auditor, semakin rendah kecenderungan melakukan perilaku audit disfungsional. Dengan demikian, H5 diterima.

\section{Pembahasan}

Penelitian ini menunjukkan bahwa budaya etis organisasi, komitmen profesional, serta tekanan anggaran waktu berpengaruh terhadap perilaku audit disfungsional. Pada hipotesis 1, Hasil analisis data penelitian yang telah dilakukan menunjukkan bahwa tekanan anggaran waktu secara parsial berpengaruh secara positif dan signifikan terhadap perilaku audit disfungsional. Jika tekanan anggaran waktu dirasakan semakin tinggi oleh auditor, maka dorongan untuk melakukan perilaku audit disfungsional semakin tinggi pula. Hasil penelitian ini sejalan dengan penelitian yang dilakukan oleh Otley \& Pierce (1996), yang menyatakan bahwa tekanan anggaran waktu menjadi faktor utama yang mendorong auditor melakukan perilaku audit disfungsional. Hasil penelitian ini juga mendukung temuan Silaban (2009), yang menyatakan bahwa tekanan anggaran waktu secara signifikan mempengaruhi perilaku audit disfungsional.

Auditor yang menghadapi persoalan anggaran waktu, akan merasakan adanya tekanan pada pekerjaannya sebab seringkali waktu yang dianggarkan untuk menyelesaikan tugas pemeriksaan dirasakan tidaklah cukup. Hal ini mendorong munculnya kewajiban bagi auditor untuk bisa menyelesaikan tugasnya dalam batas waktu yang ditentukan. Kewajiban yang muncul dari tekanan yang dirasakan oleh auditor tersebut menyebabkan mereka melihat anggaran waktu 
sebagai kendala untuk bisa mencapai hasil kerja yang berkualitas sehingga menyelesaikan tugas sesuai dengan target dan prosedur yang ditentukan sulit untuk dipenuhi.

Pada hipotesis 2, hasil analisis data penelitian yang telah dilakukan menunjukkan bahwa budaya etis organisasi secara parsial berpengaruh secara negatif dan signifikan terhadap tekanan anggaran waktu. Jika semakin tinggi pemahaman dan implementasi budaya etis organisasi oleh auditor, maka tekanan anggaran waktu yang dirasakan oleh auditor dalam proses audit semakin berkurang. Hasil penelitian ini sejalan dengan Svanberg \& Ohman (2013), yang menemukan bahwa budaya etis organisasi berpengaruh negatif terhadap tekanan anggaran waktu. Dengan kata lain, praktek penganggaran waktu yang ketat terjadi pada entitas bisnis yang memiliki budaya etis yang lemah.

Dalam institusi pemeriksa (BPK), budaya etis organisasi yang mendukung suasana kondusif dalam bekerja yang ditunjukkan oleh para atasan menjadi kunci penting dan menentukan dalam mencegah terjadinya perilaku-perilaku menyimpang organisasi dalam melaksanakan tugas audit mereka. Ketika auditor merasa bahwa budaya etis ditegakkan oleh oleh atasan mereka, atau ketika para auditor merasa bahwa pimpinan memberikan perhatian terhadap isu-isu etis dan berbagai pelanggaran etis yang dilakukan oleh para bawahan, serta melihat bahwa setiap pelanggaran etika organisasi akan dihukum atau diberikan sangsi tegas, maka mereka (auditor) tidak akan mengalami kendala terkait dengan batasan waktu pelaksanaan tugas yang diberikan.

Pada hipotesis 3, hasil analisis data penelitian yang telah dilakukan menunjukkan bahwa budaya etis organisasi secara parsial berpengaruh secara negatif dan signifikan terhadap perilaku audit disfungsional. Jika semakin tinggi pemahaman dan implementasi budaya etis organisasi oleh auditor, maka dorongan untuk melakukan perilaku audit disfungsional semakin menurun. Hasil ini sejalan dengan penelitian yang dilakukan oleh Lightner et al (1982), yang menyatakan bahwa kepercayaan seseorang atas norma yang dirasakan menjadi faktor penting dalam menjelaskan apakah seorang akuntan melakukan Perilaku audit disfungsional, yang dalam hal ini adalah underreporting time atau tidak. Hasil 
peneletian serupa juga ditemukan oleh Sweeney et al (2010), yang menyatakan bahwa budaya etis yang melelkat pada sesorang dalam organisasi mempengaruhi seseorang untuk berperilaku disfungsional. Bukti empiris yang menguatkan pengaruh budaya etis terhadap perilaku audit disfungsional ditunjukkan dalam penelitian Svanberg \& Ohman (2013), bahwa budaya etis organisasi berpengaruh negatif terhadap perilaku audit disfungisonal.

Budaya etis organiasi menjadi faktor penting yang secara signifikan terhadap proses pelaksanaan tugas audit BPK di lapangan. Suasana kondusif yang tercipta dalam organiasasi yang ditunjukkan oleh pimpinan organisasi dan dengan demikian memberikan pengaruh pada para bawahan akan menghindarkan para auditor untuk mengurangi kualitas audit dalam setiap pelaksanaan tugas audit mereka. Auditor yang menyadari pentingnya budaya organisasi mereka secara etika tidak akan melakukan tindakan yang berpotensi mengurangi kualitas audit, seperti pengentian prosedur audit secara prematur, review dokumen yang tidak dilakukan sebagaimana mestinya, tidak melakukan pengujian seluruh sampel yang diambil, tidak berusaha mendalami temuan-temuan salah saji material bukti audit auditee dan lebih mempercayai penjelasan auditee serta mengandalkan pekerjaan mereka, tidak melakukan pengujian terhadap standar akuntansi dalam dokumen auditee dan lain sebagainya.

Pada hipotesis 4, Hasil analisis data penelitian yang telah dilakukan menunjukkan bahwa komitmen profesional secara parsial berpengaruh secara negatif dan signifikan terhadap tekanan anggaran waktu. Jika komitmen profesional auditor terhadap profesi audit semakin meningkat, maka tekanan anggaran waktu yang dirasakan selama pemeriksaan akan menurun. Hasil penelitian ini sejalan dengan Choo (1986), yang menemukan bahwa auditor yang memiliki komitmen profesional yang tinggi merasakan tekanan kerja yang lebih rendah dibandingkan auditor yang berKomitmen Profesional rendah.

Auditor dengan tingkat komitmen profesional yang tinggi adalah mereka yang mencintai profesi, memberikan loyalitas serta dedikasi dalam profesi yang digelutinya. Auditor BPK yang memiliki komitmen profesional afektif yang tinggi yang terrefleksikan dalam bentuk kecintaan dan kebanggaan terhadap profesi 
auditor, ada keterikatan emosional terhadap profesi serta melihat auditor sebagai profesi yang sangat penting tidak akan mengalami permasalahan waktu yang digunakan dalam proses pemeriksaan. Auditor yang sepenuhnya mendedikasikan kehidupannya untuk memajukan profesi auditor akan bekerja keras dan sungguhsungguh melihat audit sebagai sebuah pekerjaan yang penting untuk dilakukan sehingga betapapun rentang waktu yang diberikan tidak terlalu banyak, namun mereka tidak merasakan adanya tekanan ataupun ketidakcukupan dalam waktu pekerjaan.

Pada hipotesis 5, Hasil analisis data penelitian yang telah dilakukan menunjukkan bahwa komitmen profesional secara parsial berpengaruh negatif dan signifikan terhadap perilaku audit disfungsional. Jika komitmen profesional auditor terhadap profesi audit semakin meningkat, maka dorongan untuk melakukan perilaku audit disfungsional semakin menurun. Hasil penelitian ini sejalan dengan Kaplan \& Whitecotton (2002), yang menemukan bahwa auditor dengan komitmen profesional tinggi memiliki niat yang lebih tinggi untuk melaporkan tindakan yang diragukan dibandingkan dengan auditor dengan komitmen profesional rendah.

Auditor yang mencintai pekerjaannya sudah pasti akan menjaga setiap sikap dan perbuatannya dari hal-hal yang merugikan profesi dan organisasinya. Komitmen Profesional membuat auditor merasa bahwa pekerjaannya merupakan salah satu kewajiban moral yang harus dijalaninya sehingga kewajiban tersebut akan menjaga auditor dari perilaku disfungsional dalam pelaksanaan tugas auditnya. Tanggung jawab, kesetiaan, serta kewajiban moral terhadap profesi audtior yang dimiliki oleh auditor BPK (komitmen normatif) berimplikasi pada profesionalisme dalam melakukan pekerjaan audit. Auditor dalam situasi ini tidak akan toleran terhadap kualitas hasil audit, dalam artian melaksanakan seluruh prosedur audit yang ditetapkan tanpa mengganti, mengurangi ataupun menghentikannya. 


\section{KESIMPULAN DAN SARAN}

Budaya etis organisasi dan komitmen profesional secara parsial berpengaruh negatif terhadap perilaku audit disfungsional. Sementara itu, tekanan anggaran waktu berpengaruh positif terhadap perilaku audit disfungsional. Lembaga pemeriksa (BPK), berdasarkan hasil penelitian ini diharapkan dapat meningkatkan budaya etis dalam organisasi serta komitmen profesional bagi para anggota (auditor) sendiri sehingga perilaku audit disfungsional dapat dikurangi atau dicegah. Peneliti selanjutnya diharapkan dapat mengekplorasi lebih banyak lagi variabel yang belum diangakt dalam penelitian ini sehingga menambah khasanah pengetahuan dalam riset audit.

\section{DAFTAR PUSTAKA}

Choo F. 1986. "Job Stress, Job Performance, and Auditor Personality Characteristics", Auditing: A Journal of Practice and Theory, Vol. 5 No.2, pp. 17-34.

Coram P Juliana N. J \& Woodliff D. 2003. "A Survey of Time Budget Pressure and Reduced Audit Quality Among Australian Auditors", Australian Accounting Review, Vol. 13 No. 1, pp. 38-45.

Kaplan \& Whitecotton S.M. 2001. “An Examinantion of Auditor's Reporting Intentions When anaother Auditor is Offered Client Emplyoment". Auditing: A Journal of Practice and Theory. Vol. 20. pp. 45-63.

Kelley T. \& Seiler R. E. 1982. "Auditor Stress and Time Budget". The CPA Journal, December. pp. 24-34

Kuncoro M. 2009. Metode Riset untuk Bisnis dan Ekonomi Edisi Ketiga. Jakarta: Erlangga.

Lightner S. S., Adams S. \& Lightner K. 1982. "The Influence of Situasional, Ethical and Expentancy Theory Variables on Accountants' Underreporting Behavior". Auditing: Journal of Practice and Theory. Vol. 2. pp. 1-12.

Malone C.F. \& Robert R. W. 1996. "Factors Associated With the Incidence of Reduced Audit Quality Behavior". Auditing: A Journal of Practice and Theory. Vol. 15. No. 2: pp. 49-64.

Otley D.T. \& Pierce B. J. 1996. "Audit Time Budget Pressure: Consequence and Antecendents". Accounting, Auditing and Accountability Journal. Vol. 9 No. 1. pp. 31-58.

Raghunathan B. 1991. Premature Sign-off of Audit Procedures: An Analysis. Accounting Horizon. Vol. 5 No. 7. Pp. 71.

Sarwono J. 2006. Metode Penelitian Kuantitatif dan Kualitatif. Yogyakarta. Penerbit Graha Ilmu. 
Silaban A. 2009. Perilaku Disfungsional Auditor dalam Pelaksanaan Program Audit (Studi Empiris di Kantor Akuntan Publik). Disertasi. Universitas Diponegoro. Semarang.

Svanberg J. \& Ohman P. 2013. Auditors Time Pressure: Does Ethical Culture Support Audit Quality?. Managerial Accounting Journal Vol. 28 No. 7 pp. $572-591$

Sweeney B., Arnold D. \& Pierce B. 2010. The Impact of Perceived Ethical Culture of the Firm and Demographic Variables on Auditors' Ethical Evaluation and Intention to Act Decisions. Journal of Business Ethics, Vol. 93, No. 4, pp. 531-551

Trevino L.K. 1986. "Ethical Decision Making in Organizations: A Person Situation Interactionist Model”. Academy of Management Review. Vol. 11 No. 3. pp. 601-617.

Willet C. \& Page M. 1996. "A Survey of Time Budget Pressure and Irregular Auditing Practices Among Newly Qualified UK Chartered Accountants", British Accounting Review, Vol. 28, pp. 101-120. 